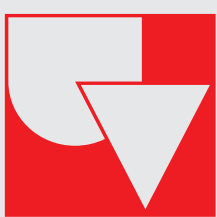

Universidad del Valle

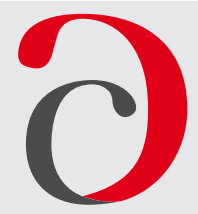

Cuadernos de

Administración

\title{
May Circular Economy make sustainability strategies financially rewarding in Latin America?
}

\author{
¿Puede la Economía Circular volver rentables las estrategias de sustentabilidad \\ en América Latina?
}

\footnotetext{
* Carlos Scheel D

Emeritus Professor, Tecnológico de Monterrey, México. e-mail: cscheel@tec.mx
}

$\begin{array}{r}\text { Editorial } \\ \text { Submitted: 31/05/2021 } \\ \text { Reviewed: 01/06/2021 } \\ \text { Accepted: 02/06/2021 } \\ \text { Published: 10/08/2021 } \\ \text { Thematic lines: Administration and Organizations } \\ \text { JEL classification: M14 M21 } \\ \text { https://doi.org/10.25100/cdea.v37i70.11489 } \\ \hline\end{array}$

Is it possible to solve the tremendous economic-environmental policy challenges imposed on developing countries' industries and governments due to the intense demands by international organizations to restrain the crisis of global warming?

Let us look at some initiatives proposed to address the environmental crisis:

a. By means of greenwashing the conventional linear chains of the most polluting industries.

b. Through public policies and strict legislation, with exorbitant fines.

c. Through extreme citizen education efforts.

d. Through innovative technologies.

The answer is none of the above. Even with the technological advancements and the growth of markets, and the governments' ambitious long-term commitments, the likelihood of adherence thereto is almost nil, mainly for developing countries, if something drastic, disruptive and comprehensive is not carried out.

The problem is complex, as it attacks the three subsystems of the natural ecosystem with high uncertainty and variability: achieving zero emissions in the environmental ecosystem, reducing the social gap, while simultaneously solving the tremendous economic "dilemma" of the 21st century: How to grow economically without ensuing severe environmental damage or great social unrest in the region.

The success of globalization, technological innovation, and exorbitant economic growth in large parts of the industrialized countries during the second half of the last century was based on low oil prices, the "excessive extraction of vast non-recoverable natural resources," the 
extensive use of technological innovation, inconsiderable human rights and relatively low salaries, yet unable to meet the basic needs mainly of the families at the Base of the Pyramid (BoP) in developing countries (Prahalad and Hart, 2002).

In the first quarter of the 21st century, other types of industries attached to industries such as digital information technologies platforms and telecommunications (ICT), energy, and pharmaceuticals, have created another socioenvironmental and economic discontinuity, much more significant in proportion than that of the past century: the "concentration of wealth" in a few, the "market monopoly" by a few corporations, and the "destabilizing social and environmental impact" created worldwide.

Although the issue of sustainability has become a priority in business strategies for hundreds of CEOs, surveyed since 2010 detected that $13 \%$ of them planned to invest in sustainability initiatives, and by 2016 that number rose to $25 \%$, current forecasts hold that it may have reduced due to other priorities, such as the pandemic, but the trend is increasing.

Those are good intentions, albeit of unlikely execution, because in the moment of truth, when a decision must be made to resolve the dilemma between implementing highly profitable business strategies with some greenwashing or reformulating less profitable sustainable businesses, the balance leans towards the economic growth.

The reason is simple: sustainability is hardly profitable and even less so if companies and governments must adhere to 0 -emissions emergency restrictions to avoid global warming in a short time.

In his 2021 book "How to avoid a climate disaster," Bill Gates outlines a series of valuable proposals, feasible solutions, and necessary breakthroughs for an effective climate change. He supports Green Premium (GP) as a mechanism to stop or reduce additional greenhouse gases to the environment.

However, although new technologies and unusual processes are necessary, they are not enough to attenuate GP costs.
During the last 20 years, technologies, high industrialization, and excessive population growth have amply concentrated wealth in the hands of a few individuals, which has been, on all accounts, unbalanced for almost all rich or developing countries. As time runs, national debts, social inequality, financial instability in the vast majority of developing countries, unemployment, corruption, lack of transparency, the poor performance of the rule of law and injustice for those who have less, excessive consumerism -associated with the excessive generation of waste-, the enormous inflow of immigrants, geopolitical instability, the enormous environmental polarity -where some regions are flooded, and other neighboring ones are droughted for several years - make the socio-economic gap increasing (Stiglitx, 2015) between those who have the most, consume the most, and those who generate the least, grow notably, mainly in developing countries (WBCSD, 2017).

This is a severe problem because, as the supply by corporate monopolies grows in the long term, extracting more and more natural resources in a predatory way will translate into lower economic growth, as companies will further compete for access to more significant volumes of increasingly scarce and more expensive resources; thus resource productivity in manufacturing (PR) and services and natural resources (ER) efficiency will be hindered in the most exploited regions of the planet. In contrast, the planet will continue to lose its ability for resilience and become unable to regain its pre-crisis levels.

Implementing business strategies that are economically successful and at the same time environmentally resilient and socially inclusive is and will be a great challenge for the 21st-century entrepreneur, even more so in the post-pandemic era.

\section{Linear optimization vs. Circular innovation}

What is Latin America (LAC) doing to mitigate the problems concerning the sustainability of the region? Not enough.

Not specifying a particular country, the big problem is that most LACs' growth depends 
For this reason, the dilemma facing the employer, the decision-maker, and the government, in general, will continue to exist if no new practices are proposed and developed to break with the conventional economic growth paradigm detached from environmental and social impact. We must break this paradigm and ensure that strategies generate sustainable increasing returns for all stakeholders, not before.

on extractive economies, low wages, and public policies reliant on a nearly null rule of law, and a myopic vision of sustainability, making sustainable and long-term growth impossible.

What are the best practices to decouple economic growth, from environmental damage, and social imbalance?

A little over ten years ago, an initiative was formalized in Europe by the entire European Union (EU) and furthered by the Ellen MacArthur Foundation in the United Kingdom to promote the notion of circular economy in business, academia, governments, and institutions to mobilize resources, procedures and policies, conducive to a sustainable and resilient region.

Although the economy has always been circular, as seen from the basic model of P. Samuelson (circa 1948) that closes the cycle between production and consumption, it is practically centered on linear chains, the GDP, the balance between supply and demand, and the concept of diminished economic returns.

The new economic innovation model is incomplete if not designed under an economically viable, inclusive, self-financing, and self-recovering approach. The goal of a regenerative and circular economy is to achieve 0-emissions, 0-garbage, 0-unemployment, (Yunus, 2017), close product and waste cycles use renewable processes, under the certainty that all materials, processes, and energies flowing through the system are sustainable-certified (Senge, Smith, Kruschwitz, Laur, and Schley, 2010).

All under a business model that is economically profitable, environmentally recoverable, and socially inclusive, durable, and valuable for the well-being of the community (Scheel, 2016; Webster, 2015).

The "circularization" of linear production models and all the traditional supply chains and customer networks through "extended responsibility" is a complicated notion if we are to implement it with the same structures that underlaid the economic growth of the 20th century.

Circularity is necessary because conventional linear models lack the ability to:

- Extend products' life cycle (usefulness life ends, but obsolete products and packaging remain for decades).

- Recovering the products already used to return them to the source of production and their suppliers.

- Transforming the material components embedded in the product into valuable goods after its useful life is over.

- Closing the life cycles of obsolete products, waste, and garbage, and revalue their materials, labor, and energy.

To achieve some circularization level in linear production chains, the relationships between individuals, markets, processes, cities, and natural resources must change (EMAF, 2015).

Thus, the flows, resources, and synergies of the entire industrial ecology ecosystem are optimized, technological and biological cycles are closed in an effective and regenerative way for the environment, producing $\boldsymbol{a}$ tremendously beneficial and differential value for all stakeholders in the region at the end of the iterations (Webster, 2015; EMAF, 2015; Scheel, 2016).

Presently, just eight products (steel, aluminum, plastic, cement, glass, wood, primary crops, and livestock) are responsible for $20 \%$ of polluting gas emissions worldwide; they use $95 \%$ of the water, $88 \%$ of usable land, and disproportionately increase the volumes of garbage and toxic waste produced globally. An effective strategy would focus on them and turn their waste into products and services of great value to the community and the attendant environment.

This is where the CE makes a significant impact, as it is necessary to decouple economic growth from environmental damage, substituting natural resources, creating valuable products from garbage and waste, new jobs, new startups, thereby creating a self-sufficient economy of increasingly sustainable returns for the inhabitants of the region. 
For example, dehydrating the cement from the demolition of buildings no longer in use, to reuse it, as Geneva does, manufacturing "all" PET plastic bottles out of recycled material, valuable for other uses; recovering textile garments no longer used for reuse; transforming all foods on the verge of decomposing into restaurant-suitable menus; converting the "residues" of nopal, agave, orange, avocado, tomato, nejayote, coffee, etc., into high commercial, functional value products for the communities where harvesting or production is processed, which are usually left with all the residue and waste. All of this is possible yet expensive. That is why we must find another type of process, of systems.

Circularization implies implementing three necessary actions, yet challenging to carry out at present, due to the industrial conditions in some areas of the world:

- Monetizing the expenses of remediation, recovery, and revaluation of waste, garbage, and obsolete products generated by companies' linear value chains.

- Insert those regeneration costs within companies' production costs.

- Transferring all the costs to the product selling price, which requires an "extended responsibility" that brings inequality against competitors who do not perform as such within the same industry as well.

This is a widespread and complex innovation that requires culturalization (in systems thinking), innovation (disruptive, systemic, and circular), enabling technologies (mainly digital, 0-emissions, clean, green technologies), holistic management of the synergies between all resources, processes, and products (industrial ecology), and the governance of all the institutions intervening in a harmonized way. Thereby, a region becomes a sustainable and resilient model when it has an economic growth, while becoming environmentally and socially prosperous.

Returning to the question at the beginning, we can affirm that a region is capable of formulating and implementing a circular business strategy, when provided that it is neither a patch-up nor a practice or process to be subsequently added to an already established business strategy, or a State strategy, only to meet a standard or a politically correct trend. It must be a strategy that, in a way, will depend on the capabilities and external sociopolitical conditions of the country where the companies, their supplier value chains, clients, and competitors co-exist in harmony.

In short, if the environmental damage generated by the industrialization of conventional chains, mainly in Latin America, is to be remedied or regenerated, it is necessary to break from the last century's linear innovation and redesign the basic structures to achieve circular innovation; there is no other alternative (EMAF, 2015).

Such is a disruptive transition, which currently requires the participation of citizens, the production sector, the government, the academy, and cites' administration, and it is perhaps the most relevant cultural and technological change since the first industrial revolution for Latin America, due to environmental risk and social imbalance the planet finds itself facing nowadays.

\section{References}

Ellen MacArthur Foundation [EMAF]. (2015). Growth within: A circular economy vision for a competitive Europe. McKinsey Center for Business and Environment.

Gates, B. (2021). How to avoid a climate disaster. Double Day.

Prahalad, C. K., \& Hart S. L. (2002) The Fortune at the Bottom of the Pyramid: eradicating poverty through profits. Strategy and Business Magazine, (26). https://www.strategy-business. com/article/11518

Scheel, C. (2016). Beyond sustainability. Transforming industrial zero-valued residues into increasing economic returns. Journal of Cleaner Production, 131, 376-386. https://doi. org/10.1016/j.jclepro.2016.05.018

Senge, P., Smith, B., Kruschwitz, N., Laur, J., \& Schley, S. (2010). The necessary revolution: Working together to create a sustainable world. Nicholas Brealey Publishing. 
Stiglitz, J. (2015). The Great divide: Unequal societies and what we can do about them (1st ed.). W. W. Norton \& Company.

Yunus, M. (2017). A World of Three Zeros. Perseus Books.
Webster, K. (2015). The circular economy: A wealth of flows. Ellen Macarthur Foundation.

World Business Council for Sustainable Development[WBCSD]. (2017).Sd.org. Retrieved from https: // www.d.org/Programs/RedefiningValue/External-Disclosure/Reporting-matters/ Resources/Reporting-Matters-2017s

How to cite this paper?

Scheel, C. (2021). May Circular Economy make sustainability strategies financially rewarding in Latin America? Cuadernos de Administración, 37(70), e1011489. https://doi.org/10.25100/cdea.v37i70.11489

Cuadernos deAdministraciónjournal by Universidad del Valle is under licence Creative Commons ReconocimientoNoComercial-SinObrasDerivadas 4.0. Based in http://cuadernosdeadministracion.univalle.edu.co/ 